\title{
Neglected epiphyseal injuries of the distal end of the radius with ulnar impaction: analysis of distal osteotomy of both bones using a dorsal midline approach
}

\author{
Paritosh Gogna $^{1} \cdot$ Sahil Gaba $^{2} \cdot$ Reetadyuti Mukhopadhyay $^{1} \cdot \operatorname{Rajesh~Rohilla~}^{1} \cdot$ \\ Amanpreet Singh ${ }^{1}$
}

Received: 18 October 2015/Accepted: 13 July 2016/Published online: 28 July 2016

(c) The Author(s) 2016. This article is published with open access at Springerlink.com

\begin{abstract}
Background To evaluate results of a technique for treating neglected epiphyseal injuries of the distal radius with ulnar impaction.

Materials and methods This retrospective study involved six cases (four males; two females), all of whom sustained the primary injury during childhood (range 9-12 years of age). All presented with wrist deformity and ulnar-sided wrist pain. They were managed with osteotomy of the distal radius, osteotomy and shortening of the ulna, harvesting the bone grafts, and distal radioulnar joint (DRUJ) reduction performed simultaneously through a dorsal midline approach. Mean follow-up was 30 months (range 24-36).

Results Deformity correction and pain relief was observed in all patients. Flexion arc increased from an average of $60^{\circ}$ to $102.5^{\circ}$, supination from an average of $31.67^{\circ}$ to $67.50^{\circ}$, and pronation from an average of $30.83^{\circ}$ to $61.67^{\circ}$. The
\end{abstract}

Paritosh Gogna

paritosh.gogna@gmail.com

Sahil Gaba

drsahilgaba@gmail.com

Reetadyuti Mukhopadhyay

reeta_m@hotmail.com

Rajesh Rohilla

drrajeshrohilla@rediffmail.com

Amanpreet Singh

amaninpune@gmail.com

1 Department of Orthopaedics and Rehabilitation, Pt B.D. Sharma Post Graduate Institute of Medical Sciences, Rohtak, Haryana, India

2 Department of Orthopaedics, All India Institute of Medical Sciences (AIIMS), New Delhi, India mean preoperative DASH score was 87.5 , which improved to 18.72 postoperatively.

Conclusion Neglected epiphyseal injuries of the distal radius are difficult to manage and many variations are described for handing each of the associated problems. Our technique provides an option for managing this injury with an easy surgical approach, single incision, and cost effectiveness. All the four components of the surgery, which include osteotomy of the distal radius, osteotomy of the ulna, harvesting the bone grafts, and DRUJ reduction were done through a single incision and in a single sitting. Level of evidence IV.

Keywords Neglected epiphyseal injury of distal-end radius · Osteotomy · Ulnar impaction

\section{Introduction}

Malunion is the commonest deformity in adult distal radius fractures, which complicates $\sim 23 \%$ of non-surgically treated, and $11 \%$ of operatively treated fractures [1-4]. The incidence in children is much lower, as any malunion of the distal end of the radius in children usually remodels itself [5, 6]. However, this may not always occur when there is associated damage to the physeal plate, leading to partial or complete growth arrest [7]. Other factors which affect remodeling are age of the patient at the time of fracture, the distance between the fracture and the epiphyseal plate, and the extent of residual angulation following reduction [5-7]. An anatomically reduced distal radius can also lead to deformity later on due to damage to the physis [8]. Multiple attempts at reduction and late remanipulation at more than 7 days post injury are known risk factors for physeal arrest [7, 9, 10]. The incidence of 
physeal closure is $7-10 \%$ according to Lee [10]. Malunions may manifest themselves variedly, ranging from asymptomatic radiographic abnormalities to disabling deformities associated with significant pain and functional impairment $[4,11]$. Treatment in the form of corrective osteotomy was first proposed by Meyerding and Overton in 1935 [12]. Since then, many techniques have been described which have their own pros and cons. Most research in this regard has been done in adult patients.

Neglected injuries in skeletally immature patients pose unique challenges, especially those with associated physeal arrest. These injuries do not remodel completely, and the normal ulnar growth later leads to DRUJ dislocation and ulnar impaction. If recognized early, physeal bar excision and fat interposition, along with distal ulnar epiphysiodesis can be done [13]. However, once ulnar abutment or impingement is present and potential for growth is over, a more invasive procedure is usually required. Neglected distal radius malunion with positive ulnar variance and distal radioulnar joint (DRUJ) disruption is a challenging situation for the surgeon. We describe our results with a simple technique in which all four components of the surgery, which include osteotomy of the distal radius, osteotomy of the ulna, harvesting the bone grafts, and DRUJ reduction can be done through a single incision and in a single sitting.

\section{Materials and methods}

This retrospective study involved six patients (four males and two females) who presented to us with the chief complaints of unsightly deformity of the wrist (radial deviation and extension deformity) with ulnar-sided wrist pain and a history of injury to the wrist during childhood (range 9-12 years; mean 10.66 years). The mechanism of injury was a fall on an outstretched hand in four cases, while in two cases it was unknown. Four cases involved the dominant side, two the non-dominant side. None of these were managed by a trained surgeon at the time of initial injury, and no patient had previous medical records or radiographs. On examination there was restriction of flexion at the wrist (average $29.16^{\circ}$ ), and rotations (supination $31.66^{\circ}$ and pronation $30.83^{\circ}$ ). The piano key sign (ulnar ballottement) was positive in all cases. PA and lateral radiographs of the wrist were performed (Fig. 1), and based on it we made the diagnosis of neglected epiphyseal injury of the distal end of the radius with DRUJ disruption and ulnar impaction. Contralateral normal wrist radiographs were also obtained to aid in pre-operative planning and to ascertain the degree of angular correction needed at the osteotomy site in both sagittal (volar/dorsal tilt) and coronal (radial inclination) planes. Our diagnosis was based on

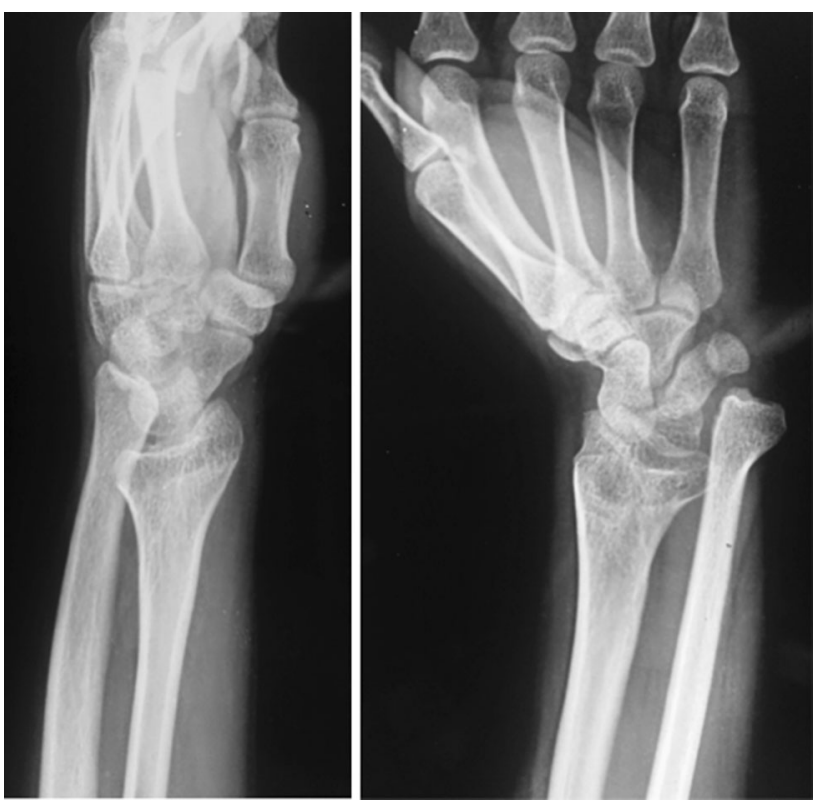

Fig. 1 Preoperative radiographs of a 21-year-old male with neglected epiphyseal injury of the distal end of the radius with DRUJ disruption and dorsal ulnar subluxation

history and radiological criteria of malunion as described by Graham [14]. Patients were taken up for surgery after written informed consent.

The surgery was performed under tourniquet control. An 8-cm longitudinal dorsal midline incision was made on the distal forearm. To begin with, an ulnar shortening osteotomy was performed, taking care that a negative ulnar variance of 1-2 mm was attained. The osteotomy site was kept as distal as possible to minimize the risk of non-union. The distal end of the ulna was then pushed proximally and fixed using a plate at the proximal end. Using the same incision, a dorsal opening wedge osteotomy was performed on the distal radius in the region of the metaphysis, which was hinged volarly. The osteotomy site was grafted using the cortical grafts harvested from the excised ulna. The graft was filled dorsolaterally to restore the volar angulation and radial inclination to within the acceptable limits (volar tilt-neutral to $20^{\circ}$ volar, radial inclination-to within $15^{\circ}$ of the normal side). The radial construct was then stabilized with two Kirchner $(\mathrm{K})$ wires, inserted from the radial styloid. The DRUJ was reduced and fixed with a partially threaded 4-mm cancellous screw inserted from the ulna to the radius in a tricortical manner. An above-elbow cast was applied postoperatively. Active finger movements were encouraged immediately after the surgery, along with limb elevation. Postoperative radiographs revealed adequate restoration of distal radius anatomy (Fig. 2). At 6 weeks the cast, $\mathrm{K}$ wires and the DRUJ screw were removed under conscious sedation and analgesia on an OPD basis, and wrist range of motion exercises were 

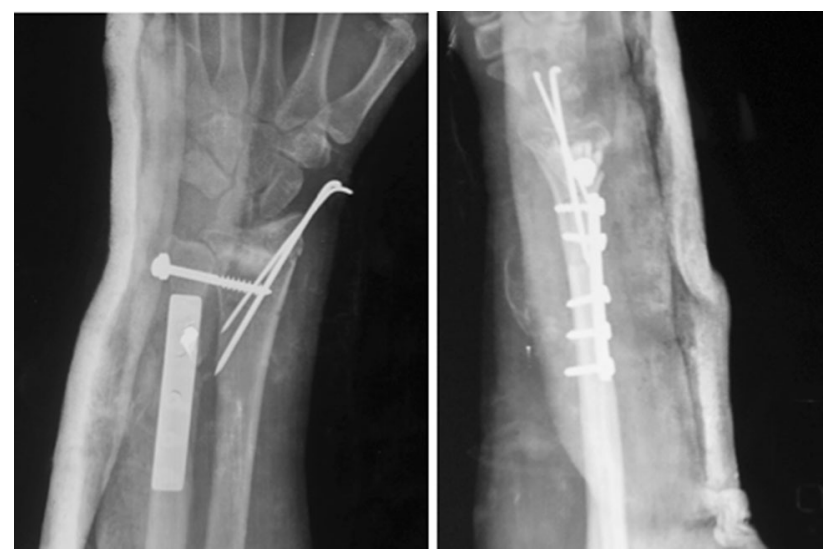

Fig. 2 Post operative radiographs of the same patient, showing restoration of distal radius anatomy

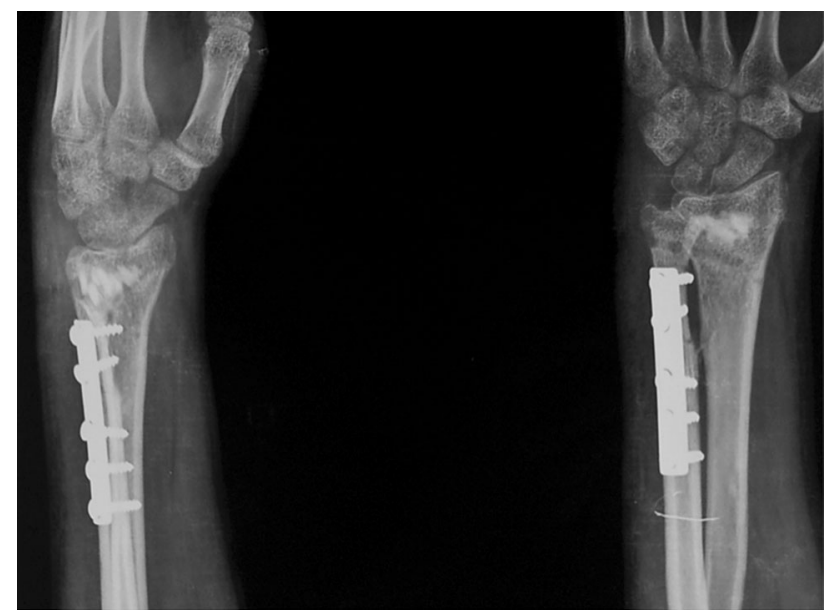

Fig. 3 Radiographs 6 weeks after the surgery, after removal of $\mathrm{K}$ wires and screw

initiated (Fig. 3). Patients were followed up monthly for 6 months and thereafter at 3-monthly intervals. At the time of final follow-up (mean 30 months; range 24 to 36 months), radiographs showed healing of the osteotomy and maintenance of radiological parameters (Fig. 4).

\section{Results}

All patients got rid of the unsightly deformity and ulnarsided wrist pain. Six months following surgery, patients noted marked improvement in flexion and rotations (Table 1). Mean dorsiflexion and palmar flexion increased by $10.8^{\circ}$ and $30.8^{\circ}$, respectively. The increase in dorsiflexion was statistically highly significant $(p=0.0062)$, as was the increase in palmarflexion $(p<0.0001)$. Mean supination and pronation increased by $35.83^{\circ}$ and $30.70^{\circ}$,

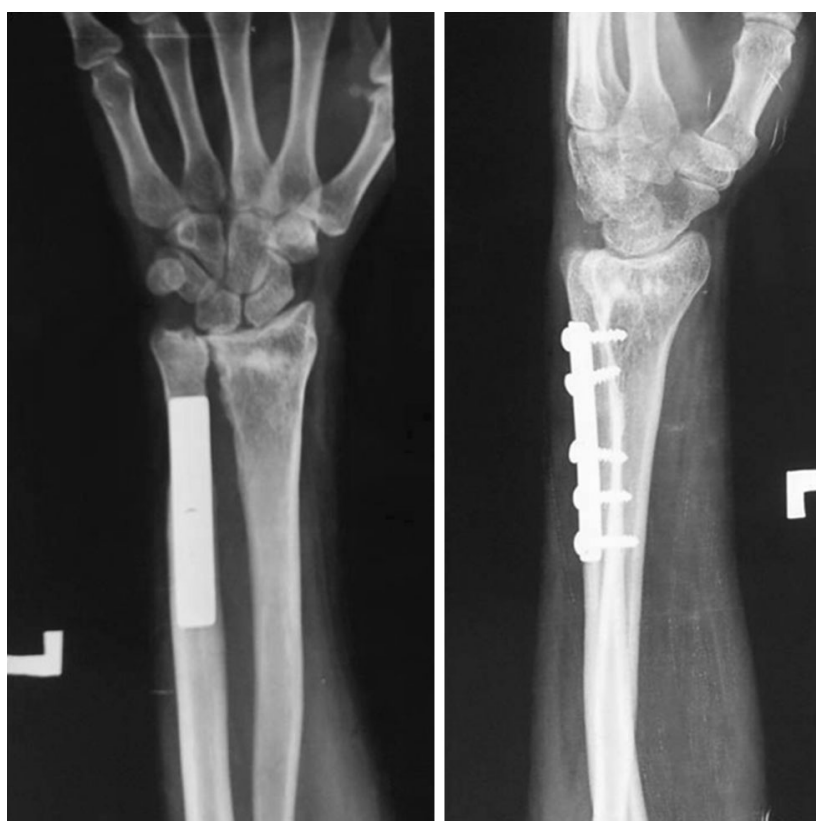

Fig. 4 Radiographs at final follow-up at 2 years

respectively. The increase in supination was highly significant $(p=0.0006)$, as was the increase in pronation $(p<0.0001)$. Total arc of flexion increased from a mean of $60^{\circ}$ to $102.5^{\circ}$. Total arc of rotation increased from a mean of $62.5^{\circ}$ to $129^{\circ}$. The mean preoperative DASH score was 87.50 , which improved to 18.73 postoperatively $(p<0.0001)$, which was highly significant. As the distal ulna had been dislocated for many years, the sigmoid notch of the distal radius may not be able to accommodate the distal ulna congruently. Hence reduction of the DRUJ after such a long time may cause incongruity of the joint and subsequent osteoarthritis. Also, the possibility of arthritis arising due to temporary arthrodesis cannot be ruled out. We performed a CT scan of the wrist at the time of final follow-up (Fig. 5) which showed a congruent sigmoid notch, but evidence of arthrosis was present in four out of six cases, although none complained of pain. The presence of arthrosis was not surprising given the duration of neglect and severity of deformities we were dealing with. All patients were satisfied with the outcome. Also, at final follow-up the radiological parameters were well maintained and DASH score improved in all patients (Table 2). During surgery, a negative ulnar variance of 1-2 $\mathrm{mm}$ was achieved in all cases (see Figs. 2 and 3 showing $2 \mathrm{~mm}$ of negative ulnar variance), but in due course of time four cases maintained a negative ulnar variance $(-1 \mathrm{~mm})$, while two cases had neutral variance (see Fig. 4). This may be due to some collapse at the radial osteotomy site. 
Table 1 Clinical details of patients

\begin{tabular}{llllllll}
\hline $\begin{array}{l}\text { S. } \\
\text { no. }\end{array}$ & Age/sex & $\begin{array}{l}\text { Age at time of } \\
\text { injury (years) }\end{array}$ & $\begin{array}{l}\text { Pre-op flexion } \\
\text { (DF/PF) } \\
\text { (degrees) }\end{array}$ & $\begin{array}{l}\text { Post-op flexion } \\
\text { (DF/PF) } \\
\text { (degrees) }\end{array}$ & $\begin{array}{l}\text { Pre-op rotation } \\
\text { (supination/pronation) } \\
\text { (degrees) }\end{array}$ & $\begin{array}{l}\text { Post-op rotation } \\
\text { (supination/pronation) } \\
\text { (degrees) }\end{array}$ \\
\hline 1 & $21 / \mathrm{M}$ & 11 & $30 / 40$ & $40 / 70$ & $45 / 25$ & $70 / 60$ & $\begin{array}{l}\text { Final follow- } \\
\text { up (months) }\end{array}$ \\
2 & 24/M & 10 & $25 / 40$ & $30 / 65$ & $30 / 30$ & $65 / 60$ & 36 \\
3 & 22/F & 12 & $25 / 35$ & $30 / 75$ & $40 / 30$ & $70 / 70$ & 26 \\
4 & 21/M & 12 & $20 / 30$ & $35 / 65$ & $20 / 30$ & $70 / 60$ & 28 \\
5 & 22/M & 9 & $25 / 40$ & $45 / 70$ & $35 / 40$ & $60 / 60$ & 30 \\
6 & 23/F & 10 & $20 / 30$ & $30 / 60$ & $20 / 30$ & $70 / 60$ & 36 \\
\hline
\end{tabular}

$D F$ dorsiflexion, $P F$ palmarflexion
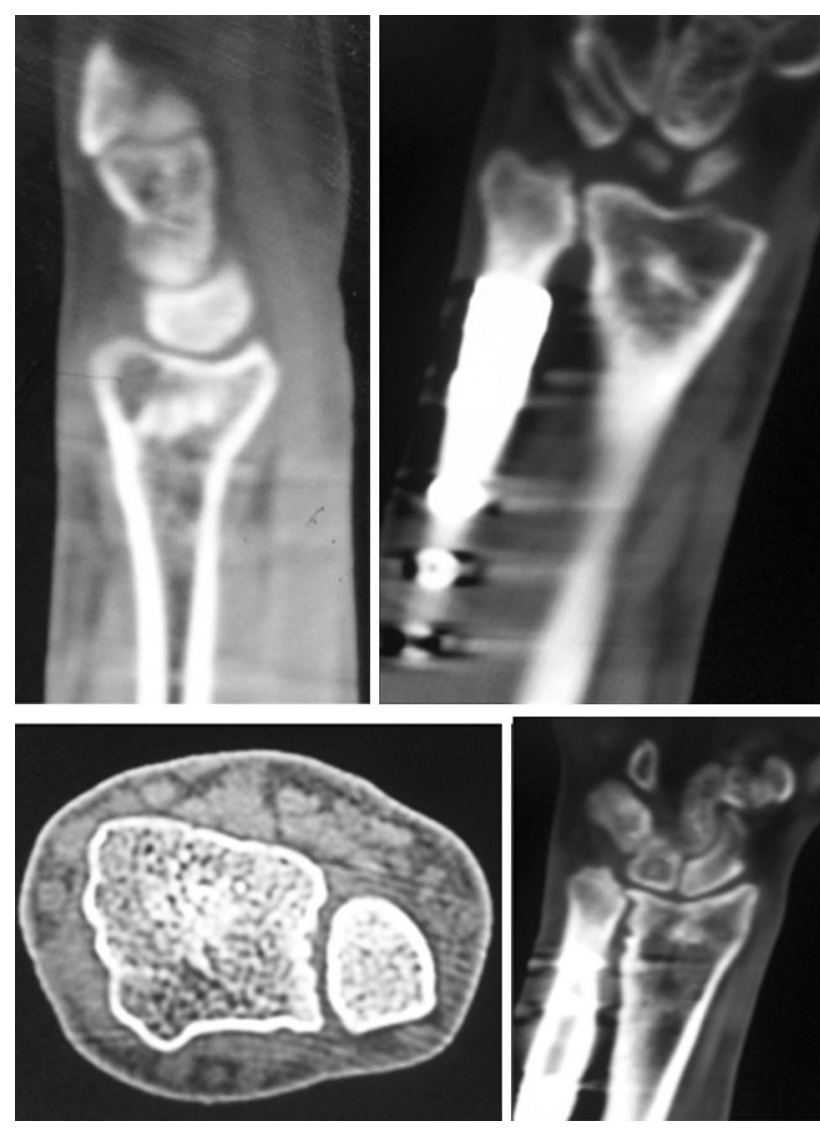

Fig. 5 CT scan of wrist of same patient at 2 years

\section{Discussion}

Malunion of the distal radius can result in biomechanical abnormalities in the radioulnar, the radiocarpal and the midcarpal joints $[15,16]$. In the normal wrist, $\sim 82 \%$ of the axial load is distributed onto the radius, with the remaining $18 \%$ being borne by the distal ulna through the triangular fibrocartilage complex (TFCC). With $2.5-\mathrm{mm}$ radial shortening, this relationship changes so that the ulna bears $42 \%$ of the axial load [17]. Continued shortening further increases ulnar load bearing and can result in symptoms of ulnocarpal impingement. Radial shortening has further deleterious effects in that it alters the congruency of the DRUJ and increases tension on the triangular fibrocartilage complex; these changes can result in increased pain and decreased rotation at the DRUJ, with nearly $50 \%$ loss in pronation and $\sim 30 \%$ loss in supination with $10 \mathrm{~mm}$ shortening. Besides causing restricted range of motion around the wrist, fractures maluniting with residual dorsal angulation and DRUJ disruption also cause an unsightly deformity [4].

Most of the epiphyseal injuries of distal radius in children are Salter-Harris type 1 or 2, and they are commonly dorsally angulated $[18,19]$. As compared to fractures of the mid shaft, the fractures of the distal forearm possess a greater remodeling potential [6], attributable to the fact that the distal growth plate of the radius accounts for $75 \%$ of the bone's length [20] which permits a substantial potential for remodeling. Age and distance from the growth plate have also been found to be important factors for the remodeling of forearm fractures in children. The potential for remodeling is maximal when the plane of deformity lies in the plane of motion of the adjacent joint [5]. Larsen et al. examined 70 fractures of the distal forearm in children with an angulation up to $28^{\circ}$ and found that children under 10 years possess the ability to correct angulation up to $28^{\circ}$, but the potential for correction is decreased with greater angulation and age over 10 years [21]. Therefore, most investigators recommend that correction of angular deformities should be performed in children over 10-12 years of age [6, 21-23]. As all our cases were in age range of 9-12 years at time of injury, all had significant growth potential remaining. Malunion in these cases, together with relative lengthening of ulna lead us to retrospectively diagnose physeal growth arrest in these cases.

Deformity in all our cases was a combination of wrist extension (due to malunion in extension) and radial deviation (due to ulnar overgrowth), although the pattern of deformity may be variable depending on the site and extent 
Table 2 Ulnar variance and DASH scores (pre-op and postop at final follow-up)

\begin{tabular}{lccll}
\hline S. no. & $\begin{array}{l}\text { Pre-op ulnar } \\
\text { variance }(\mathrm{mm})\end{array}$ & $\begin{array}{l}\text { Post-op ulnar variance } \\
(\mathrm{mm}) \text { (final follow-up) }\end{array}$ & $\begin{array}{l}\text { Pre-op DASH } \\
\text { score }\end{array}$ & $\begin{array}{l}\text { Post-op DASH score } \\
\text { (final follow-up) }\end{array}$ \\
\hline 1 & +9 & 0 & 80 & 15.8 \\
2 & +10 & -1 & 93 & 20.8 \\
3 & +8 & 0 & 82 & 19.2 \\
4 & +10 & -1 & 90 & 17.5 \\
5 & +9 & -1 & 87 & 15.8 \\
6 & +11 & -1 & 93 & 23.3 \\
\hline
\end{tabular}

of physeal arrest. Variable loss of radial inclination was present in all cases in the coronal plane. The radial deviation was noted only several years after the injury.

Volar plates have been used with success to treat malunions of the distal radius by combining them with a corrective osteotomy [24]. The advantage of a volar plate is that it does not require cast immobilization. The dorsal defect that is created after the opening wedge osteotomy requires filling with an appropriate bone graft. The graft may be packed in via the volar exposure; however, a limited dorsal approach is indicated to improve visualization. A volar approach not only involves thorough surgical dissection but also necessitates a separate incision for addressing ulnar shortening [4]. For dorsally angulated fractures, techniques involving a dorsal approach and fixation are known to improve radiological parameters, as well as pain and function [4, 24]. Wieland, Dekkers and Brink reported good results in their series of malunited distal radius fractures using a dorsal open wedge osteotomy with a dorsal plate without bone graft [25]. However, a prominent dorsal implant, extensor tenosynovitis, and rupture of extensor tendons have been reported as complications after use of a dorsal plate. Moreover, dorsally placed implants have thicker plates, raised screw heads, and they lack the ability to contour the plate to fit the bone $[26,27]$. Though the advent of low-profile dorsal plates has solved this concern to some extent, this technique often requires dissection of the extensor retinaculum, and sometimes resection of Lister's tubercle [27, 28].

The current technique retains the advantages of the dorsal approach, namely excellent exposure of the radius and ulna and minimal surgical dissection, and by using Kirschner wires instead of plate, the complications associated with dorsal plating are ameliorated. There is no need for a formal second surgery for implant removal, as $\mathrm{K}$-wires and DRUJ screws were removed in an OPD setting. The excised ulna is used as a graft, further mitigating the morbidity associated with graft harvesting. The biggest advantage of the technique is that all the four components of the surgery, which include osteotomy of the distal radius, osteotomy of the ulna, harvesting the bone grafts and DRUJ reduction can be done through a single incision and in a single sitting. Also, cost of surgery is minimal, as we did not use volar locking plates. Though this technique requires cast immobilization, with aggressive physiotherapy good range of motion is gained.

Our recommendation is to utilize this technique for addressing neglected epiphyseal injuries leading to dorsal angulation of the distal radius, with positive ulnar variance and DRUJ disruption, as it leads to optimal outcome and minimal morbidity. However, studies with larger sample size and longer follow-up are required to further support this observation.

\section{Compliance with ethical standards}

\section{Conflict of interest None.}

\section{Source of funding (financial affiliations) None.}

Ethical standards All patients gave informed consent prior to being included in the study. All procedures were in accordance with the 1964 Helsinki Declaration and its later amendments. The study was approved by the research ethics committee.

Open Access This article is distributed under the terms of the Creative Commons Attribution 4.0 International License (http://crea tivecommons.org/licenses/by/4.0/), which permits unrestricted use, distribution, and reproduction in any medium, provided you give appropriate credit to the original author(s) and the source, provide a link to the Creative Commons license, and indicate if changes were made.

\section{References}

1. Pogue DJ, Viegas SF, Patterson RM, Peterson PD, Jenkins DK, Sweo TD et al (1990) Effects of distal radius fracture malunion on wrist joint mechanics. J Hand Surg Am 15(5):721-727

2. Slagel B, Luenam S, Pichora D (2007) Management of posttraumatic malunion of fractures of the distal radius. Orthop Clin N Am 38(2):203-216

3. Prommersberger KJ, Froehner SC, Schmitt RR, Lanz UB (2004) Rotational deformity in malunited fractures of the distal radius. J Hand Surg Am 29(1):110-115

4. Lodha SJ, Wysocki RW, Cohen MS (2011) Malunions of the distal radius. In: Chung $\mathrm{KC}$ (ed) Hand surgery update V. American Society for Surgery of the Hand, Rosemont, pp 125-137

5. Blount WP (1940) Forearm fractures in children. Clin Orthop 51:93-107 
6. Gandhi RK, Wilson P, Mason Brown JJ, Macleod W (1962) Spontaneous correction of deformity following fractures of the forearm in children. Br J Surg 50:5-10

7. Houshian S, Holst AK, Larsen MS, Torfing T (2004) Remodeling of Salter-Harris type II epiphyseal plate injury of the distal radius. J Pediatr Orthop 24(5):472-476

8. Nietosvaara Y, Hasler C, Helenius I, Cundy P (2005) Marked initial displacement predicts complications in physeal fractures of the distal radius: an analysis of fracture characteristics, primary treatment and complications in 109 patients. Acta Orthop 76(6):873-877

9. Beaty JH, Kasser JR (2009) Fractures of the distal radius and ulna. In: Rockwood and Wilkins' fractures in children, 7th edn. Lippincott Williams and Wilkins, Philadelphia, pp 306-307

10. Lee BS, Esterhai JL, Das M (1984) Fracture of the distal radial epiphysis. Clin Orthop Relat Res 185:90-96

11. Cannata G, De Maio F, Mancini F, Ippolito E (2003) Physeal fractures of the distal radius and ulna: long-term prognosis. J Orthop Trauma 17(3):172-179

12. Meyerding HW, Overton LM (1935) Malunited fracture of the lower end of the radius (Colles' fracture) treated by osteotomy. Minn Med 18:84-89

13. Abzug JM, Little K, Kozin SH (2014) Physeal arrest of the distal radius. J Am Acad Orthop Surg 22(6):381-389. doi:10.5435/ JAAOS-22-06-381

14. Graham TJ (1997) Surgical correction of malunited fractures of the distal radius. J Am Acad Orthop Surg 5:270-281

15. Bronstein AJ, Trumble TE, Tencer AF (1997) The effects of distal radius fracture malalignment on forearm rotation: a cadaveric study. J Hand Surg Am 22(2):258-262

16. Adams BD (1993) Effects of radial deformity on distal radioulnar joint mechanics. J Hand Surg Am 18(3):492-498

17. Gogna P, Selhi HS, Mohindra M, Singla R, Thora A, Yamin M (2014) Ulnar styloid fractures in distal radius fractures managed with volar locking plate: to fix or not? J Hand Microsurg 6(2):53-58

18. Aitken AP (1935) The end results of the fractured distal radial epiphysis. J Bone Jt Surg 17(2):302-308

19. Aitken AP (1935) Further observations on the fractured distal radial epiphysis. J Bone Jt Surg 17(4):922-927

20. Salter RB, Harris WR (1963) Injuries involving the epiphyseal plate. J Bone Jt Surg Am 45:587-622

21. Larsen E, Vittas D, Torp-Pedersen S (1988) Remodeling of angulated distal forearm fractures in children. Clin Orthop 237:190-195

22. Crawford AH (1988) Pitfalls and complications of fractures of the distal radius and ulna in childhood. Hand Clin 4:403-413

23. Davis DR, Green DP (1976) Forearm fractures in children. Pitfalls and complications. Clin Orthop 120:172-184

24. Mahmoud M, El Shafie S, Kamal M (2012) Correction of dorsally-malunited extra-articular distal radial fractures using volar locked plates without bone grafting. J Bone Jt Surg $\mathrm{Br}$ 94(8):1090-1096

25. Wieland AW, Dekkers GH, Brink PR (2005) Open wedge osteotomy for malunited extra-articular distal radius fractures with plate osteosynthesis without bone grafting. Eur J Trauma $31: 148-153$

26. Jupiter JB (1999) Plate fixation of fractures of the distal aspect of the radius: relative indications. J Orthop Trauma 13(8):559-569

27. Simic PM, Robison J, Gardner MJ, Gelberman RH, Weiland AJ, Boyer MI (2006) Treatment of distal radius fractures with a lowprofile dorsal plating system: an outcomes assessment. J Hand Surg Am 31(3):382-386

28. Yu YR, Makhni MC, Tabrizi S, Rozental TD, Mundanthanam G, Day CS (2011) Complications of low-profile dorsal versus volar locking plates in the distal radius: a comparative study. J Hand Surg Am 36(7):1135-1141 